East African Medical Journal Vol. 80 No 4 April 2003

EFFECTS OF THEOPHYLLINE ADMINISTRATION AND INTRACRANIAL ABNORMALITIES ON PROTECTIVE HEAD TURNING RESPONSE IN PRETERM INFANTS

A. Wasunna, Associate Professor, MBChB, MMed, Fell. Neonate Med.(Lond) Department of Paediatrics and Child Health, Faculty of Medicine, College of Health Sciences, University of Nairobi, P.O. Box 19676, Nairobi, Kenya

\title{
EFFECTS OF THEOPHYLLINE ADMINISTRATION AND INTRACRANIAL ABNORMALITIES ON PROTECTIVE HEAD TURNING RESPONSE IN PRETERM INFANTS
}

\section{A. WASUNNA}

\begin{abstract}
Objective: To determine effects of theophylline therapy for recurrent apnoea of prematurity and abnormal early (within the first 24 hours) cranial ultrasound abnormalities on protective neck turning response in preterm infants.

Design: A cross sectional descriptive study.

Setting: The Neonatal Unit of Hammersmith Hospital, London over a period of four months (February to May 1987) and the babies followed up for six months after discharge.

Main Outcome Measures: Preterm babies of gestation 25 to 33 weeks confirmed by early postnatal Dubowitz assessment were studied. All infants had cranial ultrasound examination within the first 24 hours of birth. Protective side turning response was recorded for each baby weekly until discharge. The pattern of maturation of the response was then analysed.

Results: Thirty preterm infants (mean gestation 30 weeks) were studied. The babies treated with theophylline had significant $(\mathbf{p}=\mathbf{0 . 0 0 4})$ delay in the maturation of the response. This improved within two weeks of stopping treatment. Eight infants had intracranial haemorrhage and seven had periventricular density. Both these groups were similar with respect to the maturation of the response. No significant interaction was found between theophylline therapy and abnormal cranial ultrasound as regards the protective side turning response. Six months follow up showed no serious neurological abnormalities among the infants.

Conclusion: Theophylline administration and perinatal brain injury may have a delaying effect on protective head turning response in the neonatal period and therefore should be taken into account during neurological examination of the preterm neonate. This effect does not seem to result in any significant long-term neurological sequelae.
\end{abstract}

\section{INTRODUCTION}

The spinal extensor activity accompanying protective side turning of the head, elicited by placing the newborn infant in prone position with the nostrils partially occluded and observing the reaction of the infant is one of the items included in the neonatal neurological assessment(1). Its postnatal maturation is in three stages; (i) slow head side roll assisted by gravity with minor pelvic movement, in the early newborn period (ii) head extension combined with active total spinal contraction (iii) head extension and rotation without observed spinal extension in the older infants.

Comparing term and preterm infants or among the preterm infants, low gestational age infants (LGA 31 to 38 weeks), and very low gestational age infants (VLGA) under 31 weeks had shown no significant differences in the maturation of the response at any postmenstrual age (PMA) $(2,3)$. In term infants, the absence of the response was reported to be associated with abnormal neurodevelopmental outcome(4). When it was considered together with the ratio of the upper to lower limb resistance to passive movement in preterm infants, its quantitative maturation was found to be significantly related to later motor development, lower maturation scores being associated with poor motor outcome(3).

Preterm infants often suffer from several clinical problems related to prematurity, many of which require intervention including medication. Little is known about the effects some of the medication given to them over long periods of time, in particular theophylline, on this response. This study set out to determine whether infants who had theophylline therapy for recurrent apnoea and those with abnormal early ultrasound examination (within the first 24 hours) showed any deviance in the maturation of this response.

\section{MATERIALS AND METHODS}

Preterm infants of gestational age 25 to 33 weeks were studied. Their gestation was determined from the obstetric ultrasound examination before 20 weeks of pregnancy, where this was available, or the month's date of the last menstrual period was used. In all infants, the gestational age was confirmed 
by early postnatal Dubowitz assessment(5). The study was conducted in the Neonatal Unit of the Hammersmith Hospital, London from February to May 1987 and then the babies were followed up for six months.

All the infants had cranial ultrasound examination within the first 24 hours of birth.

The Protective Side Turning of the Head: The infants were examined for this response weekly from the first week of life until they were discharged. The assessments were performed during the awake states III or IV (6) and half an hour before the next feed as part of the weekly neurological examination for their management. The person assessing the response was blind to the medication the infants were on and the cranial ultrasound findings. The assessment was postponed on any jaundiced infant. At the time of discharge, the clinical notes of each infant were reviewed and any assessments recorded during episodes of infection or during the period the infant was on medication other than theophylline were removed from the future analysis. The examination method and grading of the responses as described by Lacey et al(3) was adopted. The five grades of response described by the authors are: Slow head side roll assisted by gravity around the infant's lengthened antero-posterior head shape, but initiated by minor pelvic movement; Head extension combined with active total spinal extension, the stronger spinal extension causing the pelvis to elevate from the bed; Head extension combined with active total spinal contraction, but without Pelvic elevation; Head extension accompanied by only thoracic extension; Head extension and rotation without observed spinal extension.

A response of grade 2 or better at 34 weeks PMA in normal preterm infant reported by the same author was taken as the baseline from which an analysis of deviance was performed using the GLIM computer programme(3).

\section{RESULTS}

A total of 30 preterm infants comprising 15 VLGA (eight male and seven female) and 15 LGA (seven males and eight females) neonates were assessed for the response on 196 occasions. Of the VLGA infants, 11(73.3\%) were treated with theophylline and $10(66.7 \%)$ had abnormal cranial ultrasound findings, which included all grades of haemorrhage, ventricular dilatation, periventricular density, leucomalacia and cysts. Their mean (range) birthweight was 1096 (600-1800) grams. The corresponding figures for the LGA infants were five $(33.3 \%)$, nine(60\%) and 1570.7 (950-2300) grams respectively. The overall mean (range) gestation and birthweight were 30(25-33) weeks and 1333.4 (600-2300) grams respectively.

The infants treated with theophylline were noted to have a significant $(\mathrm{P}=0.004)$ delay in the maturation of the response, which improved within two weeks of stopping treatment.

Eight infants with haemorrhage on cranial ultrasonography were not significantly different from seven with periventricular density with respect to maturation of the response.

No significant interaction was found between theophylline therapy and abnormal cranial ultrasound.
Follow up of the infants at six months revealed only mild dystonic abnormalities in five infants, four of whom had both abnormal cranial ultrasound and theophylline therapy while one had abnormal cranial ultrasound only (Table 1).

\section{Table 1}

Analysis of deviance of the response of grade 2 or better at postmenstrual age of 34 weeks

\begin{tabular}{|c|c|c|c|c|}
\hline Factor & & $\begin{array}{l}\text { Score } \\
<2\end{array}$ & $\begin{array}{l}\text { Score } \\
>2\end{array}$ & \\
\hline Theophylline & Yes & 13 & 3 & $\mathrm{P}=0.004$ \\
\hline Administration & No & 3 & 11 & $2(1)=8.47$ \\
\hline Cranial & Normal & 3 & 8 & $\mathrm{P}=0.07$ \\
\hline Ultrasound & Abnormal & 13 & 6 & $X^{2}(1)=3.23$ \\
\hline
\end{tabular}

\section{DISCUSSION}

In this study, there was found a significant $(\mathrm{P}=0.004)$ delay in the maturation of the prospective head turning response in association with theophylline or due to the effect of the problems that had precipitated the need for theophylline therapy, i.e. the apnoeic episodes. It is interesting to note that stopping theophylline therapy was associated with improved response scores within two weeks. Theophylline toxicity in the newborn infant has been reported to cause, among other things, jitteriness, convulsions, and even opisthotonos; all of which improve rapidly on stopping treatment $(7,8)$. Increased muscle tone with apparent higher response scores would be expected in association with these conditions.

All the infants who were on theophylline in this study had therapeutic blood levels of the drug and none of them showed signs of toxicity. It is difficult to know whether the hypotonia in these infants may have been due to theophylline or to the underlying disorder. Theophylline within therapeutic range may have the effect of reducing muscle tone in the neonates.

Abnormal cranial ultrasound findings were associated with delay in the maturation of this response, which approached statistical significance $(\mathrm{P}=0.07)$. It is possible that with large numbers, statistical significance could have been achieved. Seven out of eleven infants in whom anatomical diagnosis was available, Lacey et al (3) reported six with chronic brain lesions. Only five of the infants in this study had mild dystonic abnormalities on follow up at six months. Of these, four had both abnormal cranial ultrasound and theophylline therapy and one had abnormal cranial ultrasound only. One infant with periventricular leucomalacia had an apparent acceleration of the maturation of the response. This infant also had increased tone of both spinal and limb muscles and this could explain the observed high response scores. Drug treatment of the newborn infant, such as theophylline therapy, and perinatal brain injury may have a delaying 
effect on the maturation of this response and should be taken into consideration when performing neurological assessment of such infant.

\section{ACKNOWLEDGEMENTS}

To Dr. L. Dubowitz for assistance with this study and to Professor V. Dubowitz for useful criticism of the study. I would also like to thank Mr. Vic Aber for offering his help with statistics and the parents and staff of the Neonatal Unit, Hammersmith Hospital, for their cooperation during the study.

\section{REFERENCES}

1. Dubowitz, L. and Dubowitz, V. The Neurological Assessment of the Preterm and Full term Newborn Infant. Clin. In. Dev. Med. 1981 No 79, SIMP Lavernham Press, Lavenham.

2. Forslund, M. and Bjerre, J. Neurological Assessment of
Preterm Infants at Term Conceptional Age in Comparison with Normal Full term Infants. Early Hum. Dev. 1983;8:195208.

3. Lacey, J.L., Henderson-Smart, D.J., Edwards, D.A. and Storey, B. The Early Development of Head Control In Preterm Infants. Early Hum. Dev. 1985; 11:199-212.

4. Prechtl, H.F.R. Problems of Behavioural Studies in the Newborn Infant. In Advances in the Study of Behaviour, Volume 1, pp 75-96. Editors: Lehrman, D.S. and Hinde, R. 1985. Academic Press, New York.

5. Dubowitz, L.M.S, Dubowitz, V. and Goldberg, C. Clinical Assessment of Gestational Age in the Newborn Infant. J. Pediatr. 1970; 77:1-10.

6. Prechtl, H.F.R. The Neurological Examination of the Full term Newborn Infant. 2nd Edition. Clinics of Developmental Medicine, 1977. No, 63, SIMP Heinemann Medical, London.

7. Labovitz, E. and Spector, S. Placental Theophylline Transfer In Pregnant Asthmatics. J. Amer. Med. Ass. 1982; 247:786788.

8. Yeh, T.F. and Pildes, R. S. Transplacental Aminophylline toxicity in a neonate. Lancet. 1977; 1:910.

\section{ANNOUNCEMENT}

\section{TH AFRICAN HEALTH SCIENCE CONGRESS}

Venue: African Union Conference Centre Addis Ababa, Ethiopia

Sept. 28-Oct. 2, 2003

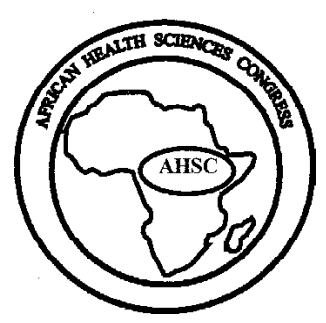

Theme:

CHALLENGES AND STRATEGIES IN COMBATING

HEALTH PROBLEMS IN AFRICA,

TOWARDS DEVELOPMENT EFFORTS

Organized by:

The Ethiopian Health \& Nutrition Research Institute (EHNRI)

\section{In collaboration with}

The African Forum for Health Sciences (AFHES),

African Union (AU) and

World Health Organization (WHO)

\section{For more details contact}

The Secretariat

24th African Health Sciences Congress

Ethiopian Health \& Nutrition Research Institute

P.O. Box 1242, Addis Ababa, Ethiopia

Tel: 251-1-766418/756310/130642; Mobile: 251-9-209071

Fax: 251-1-756329/757722

E-mail: fosnna@telecom.net.et \& tsige@enarp.com Web-site: www.kemri.org 